\title{
PRÁTICAS DE ESTUDO CONTEMPORÂNEAS E A APRENDIZAGEM DA
} ATENÇÃO CONTEMPORARY PRACTICES OF STUDY AND THE LEARNING OF ATTENTION

\author{
Beatriz Sancovschi e Virgínia Kastrup \\ Universidade Federal do Rio de Janeiro, Rio de Janeiro, Brasil
}

\begin{abstract}
RESUMO
O objetivo deste artigo é analisar a aprendizagem da atenção nas práticas de estudo dos estudantes de psicologia na contemporaneidade. Ao invés de apresentar as transformações em relação às práticas tradicionais em termos de déficit ou de falta, procuramos investigar algumas das novas formações subjetivas/cognitivas que vêm surgindo, sobretudo em função do acoplamento com as novas tecnologias. Buscamos desenhar uma cartografia da cognição contemporânea realizando entrevistas com estudantes de psicologia do município do Rio de Janeiro, utilizando a técnica da explicitação. A presença do computador-internet nas práticas de estudo, ao fazer parte do cotidiano desses estudantes, concorre por um lado para a produção de uma atenção saltitante e sem ritmo que se desdobra numa atenção suficiente e numa atenção dividida. Por outro lado, há indícios do surgimento de uma política cognitiva curiosa e desejosa de saber, que pode gerar diferentes resultados.
\end{abstract}

Palavras-chave: práticas de estudo; cognição contemporânea; aprendizado da atenção; novas tecnologias.

\begin{abstract}
The objective of this paper is to analyze the learning of attention in the practices of study of psychology students in contemporaneity. We chose to investigate some of the new subjective / cognitive formations that are emerging instead of presenting the changes in relation to traditional practices in terms of deficit. We have built a cartography of the contemporary cognition by using interviews with psychology students from Rio de Janeiro. In order to accomplish that, we used the explicitation technique. The presence of the computer-internet in the daily lives of these students and therefore on their practices of study, contributes to produce a skipping attention and an attention without rhythm, which will be transformed on a sufficient attention and divided attention. On the other hand, there are evidences of a cognitive policy that is curious and eager to learn, which can produce different results.
\end{abstract}

Keywords: practices of study; contemporary cognition; learning of attention; new technologies.

Através da ideia de que o problema da atenção pode ser colocado também a partir de sua aprendizagem (Kastrup, 2004), propomos neste artigo analisar a aprendizagem da atenção em jogo nas práticas de estudo dos estudantes de psicologia do município do Rio de Janeiro na contemporaneidade. Considerando a existência de múltiplos funcionamentos atencionais, nos afastamos das abordagens do déficit de atenção. Ao invés de apontar o déficit ou a falta, sugerimos haver novas formações subjetivas/cognitivas que merecem ser investigadas em suas singularidades. Trata-se então de realizar uma cartografia da cognição contemporânea. Neste contexto, a análise do acoplamento da cognição com as novas tecnologias ganha relevo. Conforme veremos, o computadorinternet faz parte, cada vez mais, do cotidiano dos estudantes, e dessa maneira concorre para a produção da atenção e de seus desdobramentos.

Através de entrevistas baseadas na técnica da explicitação (Vermersch, 2000), procuramos identificar como os estudantes estão estudando e qual a relação que têm estabelecido com eles mesmos e com o conhecimento em suas práticas de estudo. $\mathrm{O}$ objetivo dessa técnica é auxiliar na verbalização da ação efetuada. Ocupa-se do como dos processos e não do porquê das atividades. Quer acessar o processo, e não a sua representação. Foram realizadas e transcritas 15 entrevistas com estudantes voluntários de quatro instituições de ensino superior - duas privadas e duas públicas - entre setembro e dezembro de 2008.

De saída, ressaltamos nosso compromisso com uma política cognitiva criadora. Kastrup, Tedesco e 
Passos (2008), ao se deterem sobre as diferenças entre as abordagens das ciências cognitivas, formularam a noção de política cognitiva. Essa busca evidenciar que as diferenças entre o cognitivismo computacional - concepção que pensa o conhecimento como representação do mundo através do processamento simbólico de informações por regras lógicas - e a abordagem autopoiética-enativa - concepção que pensa o conhecimento como uma produção coengendrada do sujeito e do mundo - não são apenas diferenças teóricas, mas apontam para modos de estar no mundo e de estabelecer relações consigo, com as coisas e com o conhecimento. O conhecimento não é, portanto, um processo neutro, podendo estar atravessado por uma política criadora - abordagem autopoiéticaenativa - ou reprodutora - cognitivismo. Em relação às práticas de estudo, a política criadora caracterizase pela valorização da experiência e transformação, enfatizando o pensamento e a problematização. Já a política cognitiva reprodutora se concentra na realização de tarefas, destacando a performance.

\section{A aprendizagem da atenção}

Baseada no trabalho de Depraz, Varela e Vermersch (2002), Kastrup (2004) propõe um deslocamento nos estudos sobre a atenção. Ao invés de enfatizar - como faz a psicologia da atenção do século $X X-a$ atenção requerida nos processos de aprendizagem, destaca a possibilidade de pensarmos numa aprendizagem da atenção. Procura então discutir o papel da aprendizagem da atenção para a cognição inventiva.

Depraz, Varela e Vermersch (2002), com o intuito de investigar a experiência, desenvolvem o método do devir-consciente. Esse se afirma como um desdobramento pragmático da époché husserliana ou método da redução fenomenológica. Embora considerem a époché uma via de acesso à experiência, percebem a dificuldade que os agentes cognitivos concretos têm de colocá-la em ação. Como realizar a suspensão da atitude natural que ao voltar-se para o mundo realiza julgamentos? Como colocar entre parênteses os nossos juízos? Formulam assim a prática do devir consciente, cujo fundamento reside numa aprendizagem da atenção.

A prática do devir-consciente não é estranha às práticas cotidianas. Depraz, Varela e Vermersch (2002) referem-se à meditação budista (shamanta), à sessão de psicanálise, à oração do coração, à entrevista de explicitação, à visão estereoscópica, à sessão de escrita $\mathrm{e}$, inclusive, ao estudo. Tendo por base o trabalho desses teóricos, Cabral (2006) propõe também a leitura de literatura. No entanto, para que todas essas práticas e outras mais que possam ser incluídas na lista deem lugar ao devir-consciente, é necessário certa atitude cognitiva. Em outras palavras, é necessária uma aprendizagem da atenção, que descrevem a partir de três gestos. Esses se desenvolvem como num círculo que continuamente se entrelaça e se reativa. Apesar da circularidade, para fins explicativos, propomos uma ordem. O primeiro gesto envolve a suspensão da atenção que deve ser sustentada ao longo da prática e que implica uma ruptura em relação à atitude natural. O segundo diz respeito a uma redireção da atenção do exterior para o interior, realizada sob suspensão e, por fim, o deixar vir (letting go) ou acolhimento, que pressupõe uma atenção concentrada porém sem foco.

Em função da articulação com Depraz, Varela e Vermersch (2002), Kastrup (2004) pensa a aprendizagem da atenção do ponto de vista do devirconsciente. A questão é como cultivar o ato de devirconsciente, que é composto desses três gestos, através de práticas concretas (Kastrup, 2004, p.11). Em outras palavras, a aprendizagem da atenção é concebida a partir de uma política cognitiva criadora. Ampliaremos aqui esta ideia. Tomaremos a aprendizagem da atenção como algo inerente à vida. Trata-se de algo que se aprende através de práticas cotidianas que produzem certos efeitos. Que tipo de atenção as práticas de estudo estão produzindo?

\section{Estudo de duas horas: sobre a temporalidade da atenção}

A análise dos relatos dos estudantes de psicologia acerca de suas práticas de estudo fez emergir, dentre outras coisas, o problema da temporalidade atencional. A partir dele procuraremos abordar algumas das singularidades do funcionamento atencional contemporâneo. Ao se referirem ao tempo máximo que conseguem permanecer estudando, houve unanimidade das respostas. Os estudantes realizam no máximo duas horas seguidas de estudo:

\footnotetext{
Às vezes eu consigo estudar um dia inteiro, mas não horas seguidas. Paro um pouco. Ai vejo outra coisa que não tem nada a ver e depois eu volto. Assim, consigo, dependendo da necessidade. Se eu sei que eu tenho uma prova amanhã e eu tenho que estudar hoje então assim, e se eu sei que eu não consegui estudar antes, fazer esse preparo e tal. Provavelmente eu vou conseguir...como já aconteceu de eu virar a noite estudando, mas é...depende muito da necessidade. Eu consigo, mas não é uma coisa...Eu consigo as horas seguidas, mas com intervalos no meio com coisas, vamos dizer, aleatórias. Um e-mail...um orkut... alguma coisa que quebre essa... (E2)
} 
Depois, a pausa é necessária a fim de assegurar um bom funcionamento da atenção:

Não. Horas, horas não. No máximo umas três horas. Depois eu começo a ficar dispersa e as coisas não começam a entrar mais. Então, prefiro estudar: 'Ah, vou estudar duas horas hoje, amanhã eu estudo mais duas horas', do que ficar em casa um dia inteiro estudando, que eu sei que eu não vou dar conta. (E10)

É certo que o limite de duas horas para o estudo vai ao encontro daquilo que os teóricos consideram ideal (Mira y Lopes, 1968; Rosário, 2004). No entanto, tomar a atenção a partir de sua aprendizagem implica em recolocar o problema. A incapacidade de ultrapassar as duas horas de estudo seguidas e a necessidade de pausas passam a ser vistas como uma produção, e não como algo dado ou como um fato natural.

Muitos estudos em psicologia investigam a temporalidade da atenção como uma questão de vigilância ou de atenção sustentada. Essa é considerada de fundamental importância na medida em que as variações atencionais pressupõem diferenças na eficiência das atividades, repercutindo sobre as performances dos sujeitos. Segundo tal perspectiva, o problema da sustentação da atenção resume-se a como fazer com que a atenção se mantenha de maneira a garantir que a tarefa seja realizada com eficiência. Trata-se antes de uma questão de performance, e não de um tempo necessário à experiência de estudo.

O termo atenção sustentada nasce na psicologia como uma derivação prática do conceito de vigilância. Gómez-Iniguez, Carbonell-Vayá e Martin Del Rio (1999) explicam que, embora o conceito de vigilância seja tomado na atualidade praticamente como sinônimo de atenção sustentada, esse surgiu no início do século XX para dar conta do problema da ativação neuronal. Henry Head introduziu o termo vigilância no campo da medicina concebendo-o como um estado de alto grau de eficiência do sistema nervoso central (SNC) subjacente aos processos físicos e psicológicos, passível de alteração em função das mudanças estruturais produzidas no SNC (Gómez-Iniguez et al., 1999, p.418). Nos anos de 1940, em função de problemas práticos surgidos durante a II Guerra Mundial, Norman H. Mackowrth começou a pensar a vigilância como atenção sustentada. Era preciso dar conta do funcionamento atencional dos controladores de radar aéreo. Como sustentar a atenção por períodos de tempo prolongados mantendo a capacidade de detecção de sinais que aparecem de maneira imprevista nas telas do radar? (Gómez-Iniguez et al., 1999, p.419). Desde então, as pesquisas psicológicas sobre atenção sustentada têm sido relacionadas às atividades de monitoramento. Situações em que um observador ou ouvinte deve continuamente sustentar sua atenção a fim de vigiá-la, não deixando escapar eventos previamente identificados - alvos - que podem aparecer ou desaparecer do campo perceptivo. Para tal corrente de estudos, a atenção sustentada confunde-se com a vigilância, configurando uma atenção contínua, com foco bem definido - $\mathrm{o}$ alvo -, capaz de prontamente detectar seu aparecimento no campo perceptivo e desencadear uma ação adequada.

Mackowrth verificou através de testes - Clock Test, Synthetic Radar Test e Main Listening Test que, após os trinta primeiros minutos de execução das tarefas, a capacidade de detecção de sinais se deteriora. Como consequência, sugeriu que os controladores de radar não prolongassem suas atividades além de uma hora sem interrupção sob pena de prejudicar a eficiência do trabalho. Ora, o limite de duas horas proposto pelos teóricos do estudo aos estudantes parece caminhar ao encontro dessas pesquisas. Podemos supor então que, para eles, o estudo é tomado como uma atividade que requer uma atenção vigilante. Em outras palavras, a relação do estudante com o estudo assemelha-se à do controlador de radar com o radar. O estudante vigilante deve manter sua atenção concentrada, ciente daquilo que precisa saber, sendo capaz de detectar seu aparecimento, não deixando escapar nada. Disso depende seu êxito. Note-se como essa proposta se afasta radicalmente do estudo como experiência. Do ponto de vista da experiência, o importante não é detectar o alvo, mas sustentar a atenção a fim de deixar-se afetar pelo texto ou por qualquer outro material de estudo. Não se trata de controle ou de foco, mas de concentração e abertura. Lecerf (2006, p.41) explica como seria uma leitura que adotasse a atenção vigilante: "Para pegar o exemplo da leitura, ser vigilante significaria reencontrar tudo o que sabemos que devemos encontrar. Isso implicaria tomar o livro como objeto cuja escritura já está acabada e cujo campo de interpretação já está balisado". A vigilância, apesar da concentração, em função do foco pré-definido, impede o aparecimento da diferença inesperada e da experiência. Vale argumentar que do ponto de vista dos controladores de radar e de pessoas que realizam funções semelhantes, a hesitação diante da ação e a problematização podem representar risco de vida. Nesses casos, a atenção extremamente focada e concentrada é que é fundamental. Porém, esse não nos parece ser o caso do estudante para quem a abertura atencional pode garantir a possibilidade de fazer do estudo uma atividade de transformação de si e do mundo.

Apesar dos muitos avanços da psicologia da atenção, é nas formulações de W. James que 
encontramos um rico material para analisar a novidade trazida pelas falas dos estudantes contemporâneos. A teoria atencional jamesiana parte da distinção entre uma atenção passiva ou involuntária e uma atenção ativa ou voluntária. Através dela, aborda diferentes problemas, inclusive $\mathrm{o}$ da atenção sustentada. Apresenta duas possibilidades para sustentar a atenção: pela via do esforço ou pela via do interesse. Através do esforço consegue-se, ao menos por algum tempo, manter a atenção em um assunto e/ou lugar. No entanto, o esforço esgota-se com facilidade, além de causar fadiga. Nos termos da psicologia do século XX, o esforço implica gasto de energia através da perda de recursos atencionais, fazendo aparecer uma sensação de exaustão (Camus, 1996). Desse modo, apesar de ser possível sustentar a atenção através do esforço, essa via apresenta notáveis limitações temporais.

É interessante perceber o quanto a explicação jamesiana da sustentação atencional pela via da vontade e do esforço aproxima-se da fornecida pelos trabalhos sobre vigilância. Lá a ideia é assegurar que de tempos em tempos haja um intervalo em função do esgotamento atencional/cognitivo. James, no entanto, segue outro percurso. Ao invés de defender a necessidade de intervalos regulares, aposta no interesse. Destaca que através do interesse é possível sustentar a atenção sem lançar mão do esforço. Cita o exemplo do gênio. O gênio é aquele que fica horas entretido no mesmo assunto, refletindo sobre suas questões, sem demonstrar sinal de cansaço e também sem desviar a atenção. Como explicar esse comportamento? De acordo James, a sustentação da atenção do gênio é realizada através da atenção passiva, e não da voluntária. Por isso não requer esforço e dura mais tempo. Explica:

\begin{abstract}
A atenção sustentada do gênio que se mantém fixa em um objeto por horas e horas, é, na maior parte, de natureza passiva. A mente genial abunda em associações numerosas e originais. $O$ tema mental uma vez em ação desenvolve todo o tipo de conseqüências fascinantes e a atenção vai de uma a outra segundo a via mais interessante sem que tenha que se desencaminhar. (James, 1899/1924, p.117)
\end{abstract}

No caso do gênio, o interesse, na medida em que produz associações, faz redes, substitui a necessidade do esforço. A sustentação é obtida através da produção da rede, e não pelo esforço exercido. Tendo em vista o contexto contemporâneo, é importante tecer considerações a respeito da hipótese jamesiana. A rede formada pela cognição do gênio é produzida transversalmente, ou seja, em relação a um mesmo assunto. Produz densidade e consistência. Não se trata apenas de profundidade, mas de um estudo que se faz em diferentes níveis e em múltiplas dimensões. São variações em torno de um mesmo tema. Seria diferente se a rede fosse realizada horizontalmente, pulando de um assunto a outro, como na navegação pela Internet. Nesse caso teríamos uma abrangência maior de temas, porém tratados superficialmente. Poderíamos dizer que ao invés de sustentação da atenção teríamos, no segundo caso, uma atenção que se mantém fixa e saltitante. A atenção se mantém na medida em que os assuntos vão variando, mas não se sustenta no sentido de conseguir dar conta da variação num mesmo assunto. Ela não dura, mas é capturada. Assim, nos parece que, embora James refira-se à atenção sustentada do gênio como uma atenção sem esforço, se concebemos o esforço não como dificuldade, mas como sinônimo de concentração - tal como faz a psicologia cognitiva (Camus, 1996) -, então teríamos que admitir a existência também de um certo esforço na atenção do gênio. $\mathrm{O}$ que queremos dizer é que, apesar de não ser difícil para o gênio sustentar a sua atenção, esta sustentação implica concentração. O próprio James nos informa sobre isso ao afirmar que a dificuldade do gênio reside em sua incapacidade de desviar a atenção. Portanto, o problema não é simplesmente fazer rede. Embora a rede seja importante, a questão que precisa ser colocada é como a rede é tecida.

Podemos avançar articulando as formulações da sustentação atencional com o conceito jamesiano de fluxo do pensamento. Isto nos ajuda a pensar numa outra dimensão da temporalidade atencional que é a do ritmo. Mais especificamente interessa-nos explorar a metáfora que compara o pensamento ao voo de um pássaro. Citamos James (1890/1952, p.158): “Quando temos, de fato, uma visão geral do maravilhoso fluxo de nossa consciência, o que nos espanta, em primeiro lugar, é essa diferente rapidez de suas partes. Como a vida de um pássaro, ele parece ser feito de uma alternância de vôos e pousos".

O pensamento, assim como o voo do pássaro, é contínuo. Sua continuidade, porém, não exclui as paradas. Observando os pássaros percebemos que seus voos são entrecortados pelos pousos. Porém, menos do que interrupção, os pousos são intervalos intimamente conectados ao voo. $\mathrm{O}$ pouso não deve ser entendido como uma parada do movimento, mas como uma parada no movimento. Portanto, podemos dizer que a continuidade do pensamento é efeito justamente das articulações entre voos e pousos. A sustentação da atenção não é uniforme, mas revela um ritmo que alterna tensão e distensão, fechamento e abertura. Dessa forma, a diferença entre a atenção sustentada do gênio e a atenção fixa e saltitante não é apenas a geografia da rede - transversal ou horizontal 
- que num caso privilegia a densidade e a consistência e no outro a abrangência, mas também a presença ou ausência de ritmo. A rede do gênio segue o fluxo do pensamento, sendo tecida num ritmo que, apesar de poder assumir diferentes velocidades, coordena voos e pousos, tensão e distensão. As paradas são momentos de abertura. Já a rede da atenção fixa e saltitante é tecida por sobressaltos, não tem ritmo, mas instantes. Nesse caso, as paradas, antes de abrirem a cognição, representam deslocamentos de foco.

A fim de melhor entender essa questão do ritmo, trazemos Simone Weil, uma filósofa e operária que no início do século $\mathrm{XX}$ também trabalhou o problema da atenção. Weil, ao falar dos movimentos dos operários nas fábricas fordistas-tayloristas, referese à diferença entre o ritmo e a cadência. Explica que o primeiro supõe um intervalo que ao mesmo tempo pausa e reconecta o movimento, enquanto o segundo é formado pela justaposição de movimentos desconectados. Sobre o ritmo e a cadência:

A sucessão de seus gestos não está designada, na linguagem da fábrica, pela palavra ritmo, mas pela palavra cadência, isto é correto, visto que esta sucessão é o contrário de um ritmo. Todas as sequências de movimentos que participam do belo e se cumprem sem degradação incluem momentos de parada, breves como o relâmpago, que vêm a ser o segredo do ritmo e dão ao espectador, por sua própria extrema rapidez, a impressão de lentidão. (Weil, 1979, pp.134-135)

Para ela, o ritmo é fundamental na medida em que participa da constituição da experiência:

É natural para o homem e conveniente para ele deter-se quando fez algo, nem que seja pelo espaço de um relâmpago, para tomar consciência, como Deus no Gênese; este clarão do pensamento, de imobilidade e equilíbrio, é o que é preciso aprender a suprimir totalmente na fábrica, durante o trabalho. As manobras em máquinas não atingem a cadência exigida, se os gestos de um segundo não se sucederem initerruptamente e quase como o tique-taque de um relógio, sem algo que marque que alguma coisa acabou e outra está começando (Weil, 1979, p.135).

$\mathrm{O}$ conceito de fluxo do pensamento e a metáfora do voo do pássaro fazem ver então que, por mais sustentada que a atenção se mostre, ela não exclui as paradas. Assim como o pássaro necessita do pouso para descansar e se reorientar em relação ao voo, nossa cognição precisa das pausas. Não se trata da parada defendida pelos estudos sobre vigilância. $O$ que está em jogo não é uma interrupção em função de um esgotamento atencional que visa restaurar a capacidade cognitiva. As pausas, antes de tudo, conectam e articulam. Após as pausas não voltamos "zerados" às atividades, mas conservamos o já vivido, e isso é fundamental para os desdobramentos da ação como experiência. Dessa maneira, no caso do funcionamento atencional do gênio, as pausas não interrompem, mas conectam, conferem ritmo, tornando possível a experiência e, consequentemente, a vivência do estudo como experiência. Isto é, um estudo que não seja pautado pela ênfase na tarefa, na solução de problemas dados e na performance, mas que inclua problematizações e pensamento. Weil nos ajuda na argumentação ao defender que o intervalo que confere ritmo não implica simplesmente um não fazer, mas principalmente um ativo padecer. Não se trata apenas de parar, mas de estabelecer outra relação com o mundo e consigo capaz de deixar-se afetar pelo trabalho feito. Nos termos da autora, tomar consciência. Portanto a pausa que confere ritmo não se opõe à sustentação da atenção. Pelo contrário, graças a ela a atenção não apenas se mantém, mas é capaz de acolher a experiência.

Voltando às falas dos estudantes a respeito de sua temporalidade atencional, percebemos que as paradas às quais se referem não se encontram a princípio em oposição à ideia de sustentação da atenção. Tanto do ponto de vista da psicologia do século XX quanto da psicologia jamesiana, a sustentação atencional pressupõe pausas. A questão então que nos parece importante analisar é a qualidade dessas pausas. Apenas assim poderemos concluir sobre as especificidades do funcionamento atencional desses estudantes. O que os estudantes fazem ao parar? Será que as pausas interrompem o estudo ou será que conferem ritmo?

Conforme os relatos, após duas horas de estudo seguidas, uma pausa é necessária. Essa é preenchida de diferentes maneiras, desde atividades que parecem contribuir para a distensão e abertura da atenção, introduzindo ritmo ao estudo, como, por exemplo, o levantar-se para olhar a paisagem, comer e até tirar um cochilo, até atividades que solicitam ainda mais atenção e, em especial, o foco da atenção, como é o caso de interromper o estudo e ir checar os e-mails e ver o Orkut. Citamos as falas dos estudantes. Um deles refere-se a sua parada no estudo como uma pausa para ver a paisagem: "Eu tenho que parar um pouquinho e ir do lado de fora. Porque geralmente eu estudo no meu quarto, então ele é todo fechado. Eu vou, abro a porta, vou pro quintal, olho pras árvores e depois volto" (E12). Outro prefere comer:

É na hora que eu não aguentava mais ler o texto. Ai você fala: 'Não, agora eu vou comer'. Ai você pára, esfria um pouco a cabeça e depois você volta. Você consegue terminar a leitura mais tranquilamente $e$ 
absorver melhor o que tá sendo apresentado sem ser.. né? Aquela leitura rápida. (E1)

Um terceiro, assim como a maioria dos estudantes - vale observar a fala de E2 apresentada no início desta seção -, preenche a pausa com atividades que tensionam ainda mais a atenção, demandando foco:

Enchi o saco, vou dar um intervalo, vou dar um recreio pra mim. Eu chamo de meu recreio. Ai eu vou assistir TV, ai eu volto depois pra estudar. Ai eu me dou outro recreio pra, por exemplo, abrir o Orkut e abrir o e-mail. Ai abro, acabou o recreio eu volto. (E9)

Aí, a pausa menos do que instaurar um ritmo, interrompe.

Assim, com exceção do "olhar a paisagem" e, talvez do "comer", que parecem instaurar um funcionamento atencional aberto e sem foco, capaz de acolher os efeitos daquilo que foi realizado até então, as outras pausas são preenchidas por atividades que implicam movimento, estimulação e responsividade. A atenção ao descansar permanece tensionada e focada. No primeiro caso, podemos falar da existência de um ritmo que se alterna entre a tensão do estudo e a distensão da contemplação. Já no segundo, parece haver sobressaltos ao invés de ritmo. A atenção não distensiona, não se abre, não permite circular o fluxo do pensamento. Nesse sentido, no segundo caso - que é justamente a orientação da maioria dos estudantes -, a possibilidade do estudo desdobrar-se em experiência através de pensamento e problematizações é praticamente inexistente. É interessante notar que alguns estudantes parecem sentir a insuficiência desse tipo de funcionamento atencional marcado pela ação e pela velocidade acelerada, o que os leva a recorrer a estratégias que visam a atenuar os efeitos dessa ausência de ritmo. E14, por exemplo, tem dificuldade em conseguir produzir um ritmo no estudo em função do excesso de velocidade. A solução encontrada é então repetir até conseguir entender. Citamos:

Quando eu pego um artigo... depende do tamanho, mas um artigo médio - dez páginas, quinze páginas. Já que eu tenho esse tempo, eu pego, leio, marco, depois leio de novo. Se tiver uma coisa que eu não marquei, eu marco novamente. Porque é questão pra percepção, parece que a primeira vez que você lê, parece que você tá muito fora, tá muito disperso ainda. Mas, pelo menos comigo é assim, quando eu leio já na segunda vez, na terceira vez eu consigo... parece que as coisas funcionam melhor pra mim. Parece que o pensamento começa... igual engrenagem, vai começando...entendeu? Então eu sei que tem que ler duas no mínimo aí vai. ... Livro não. Livro, por exemplo, só quando a professora, o professor diz:
'Oh, capítulo tal'. Ai sim. Mas o livro inteiro é raro na maioria das vezes. Mas o livro inteiro, mas o livro eu já faço diferente pra ler, eu já leio devagar. ... Por exemplo, eu leio, vou tentando meditar naquilo que foi escrito ali pra pegar realmente, pra ter o entendimento daquilo, pra não passar. É claro, pô, tem dia que eu leio direto e quando você vai ver o que o livro fala: 'Ih, caraca!'. Entendeu? ... Ai tu improvisa [risos]. Sempre surge alguma coisa. Mas eu não gosto disso. (E14)

Portanto, afirmar a incapacidade de ultrapassar as duas horas de estudo é ainda insuficiente para compreendermos as especificidades do funcionamento atencional desses estudantes de psicologia. A análise das pausas e paradas é importante. Em nossa pesquisa percebemos que as paradas têm funcionado menos como distensão e abertura para que o pensamento flua e mais como interrupções para fazer outras coisas que exigem ainda mais o foco da atenção. Ao invés de ritmo, os estudantes funcionam cada vez mais por sobressaltos. A partir do que foi dito, propomos que as práticas de estudo desses estudantes estão produzindo antes uma atenção saltitante e sem ritmo do que uma atenção sustentada e ritmada. As consequências para o estudo são inevitáveis. Menos do que um estudo como experiência, as práticas têm revelado um estudo que lida com aquilo que deve ser aprendido como tarefa a ser resolvida. O objetivo é, sobretudo, a performance. Se as notas foram boas, para que se envolver mais? Uma fala de um estudante resume bem essa ideia. Ao ser indagado se havia conseguido estudar aquilo que precisava, respondeu:

Ao pé da letra, tudo o que eu tinha que ler, não. Teve texto que eu não li, mas meu desempenho na prova foi... A prova era com consulta também. De certa forma isso alterou a minha metodologia de estudo, né? Mas eu fui bem na prova, tirei 9 na prova. ... Sim, fui bem-sucedido. (E7)

\section{Atenção saltitante e sem ritmo e o acoplamento da cognição com as novas tecnologias}

Dando continuidade à análise das entrevistas, em especial nos detendo naquilo que é feito durante essas duas horas em que se diz estar estudando, a questão do acoplamento da cognição com o computador-internet apareceu com destaque. Percebemos que a presença dessas tecnologias nas práticas de estudo não é uma exceção, fazendo parte do cotidiano dos estudantes. Aí, é importante dizer, o computador-internet pode ou não estar sendo usado para fins de estudo. Aliás, compreendemos através da fala de E2 que a linha que separa o uso lúdico do computador do uso para estudo 
e/ou trabalho é tênue. De um segundo para outro, aquilo que era apenas diversão passa a fazer parte do circuito estudo-trabalho.

Um estudante narra um episódio em que estava estudando para uma prova de fisiologia enquanto seu computador estava ligado. De repente seu amigo da turma avisou através do MSN que um colega havia postado na comunidade do Orkut uns slides que ele pegou na internet justo sobre o mecanismo que era o tema da prova. Nesse momento, o computador e a comunicação virtual deixaram de ser apenas diversão e/ou distração para entrar no circuito daquilo que estava sendo estudado. Citamos um trecho:

Pode ser que sim e pode ser que não. Por exemplo, nesse dia que eu descobri esse vídeo no orkut, eu tava com o orkut aberto, era...não me lembro se era véspera da prova... Não faltava acho que tipo dois dias para prova assim. Ai o menino me mandou o link. Então por acaso eu tava com o orkut aberto e naquele mesmo momento eu já utilizei para uma coisa que aparentemente eu não ia usar. ... Serviu para eu adicionar no resumo que eu tava fazendo. (E2)

Mesmo os estudantes que relatam uma incapacidade de estudar com o computador-internet, ao revelarem a necessidade de um autocontrole permanente, nos forçam a pensar que, mesmo desligado, o computador está ainda presente em suas cognições enquanto estudam. Enfim, essa atenção saltitante e sem ritmo que vemos nascer nas práticas de estudo dos estudantes contemporâneos parece estar relacionada com os dispositivos usados pelos estudantes para estudar.

\section{Novas tecnologias e a captura da atenção}

Um estudante comenta que em seu estudo se dispersa mais com seu próprio pensamento do que com as idas e vindas para o computador:

Vai parecer engraçado, mas tipo, eu dispersava porque eu pensava em outra coisa. Mas era raro nessas minhas saidas do texto, era raro eu perder o que eu tava pensando, sabe? Normalmente... ... É. Tipo de olhar pra cima e voltar, é raro, mas às vezes eu tava lendo um tempo e começava a dispersar, sabe? ... Eu sentia indo e puxava de novo, voltava pro início do parágrafo, tipo 'opa! Peraí, eu já tô aqui, eu não lembro o que tinha nessas frases antes', ai começava tudo de novo, sabe? (E4)

O interessante é que através de sua fala notamos que o próprio estudante acha isso surpreendente. Ele usa a expressão "Vai parecer engraçado" para introduzir seu comentário. Isso nos faz pensar sobre o tipo de atenção que as novas tecnologias mobilizam. Parece tratar-se de uma captura que prende a atenção e a faz saltar entre focos distintos, impedindo que ela desvie.

Voltando às ideias desenvolvidas por James, o computador parece favorecer a construção de redes de pensamentos, o que a princípio apontaria para possibilidade de uma atenção sustentada. No entanto, ao analisar o modo como essas redes estão sendo constituídas, vamos percebendo que se tratam muitas vezes de redes horizontais que articulam, num tempo acelerado, temas sem relação. A fala de um dos estudantes é exemplar:

Eventualmente eu olhava pra tela do computador, talvez... é... sabe? Meio que... não surfar, no sentido de ficar procurando coisa, mas clicava num link ou outro que tava na janela, sabe? Tinha algumas... era... É eu ficava meio que surfando, tipo, olhava o Orkut, clicava e continuava lendo. (E4)

Mais adiante comenta sobre aquilo que estava sendo acessado junto com a leitura do texto que estava estudando:

Não, não tinha nada a ver com o assunto. Mas eu me lembro que era alguma coisa teórica também, só que nada a ver com o assunto. ... Ah é! E outra coisa, tinha o Wikipédia, o Orkut, tinha uma página do Google aberta que eu boto "define" e as palavras em inglês quando eu não sei exatamente o que ele tá falando, que aí ele dá a definição. (E4)

Desse modo, ao invés de densidade, as redes estão produzindo abrangência. Menos do que uma atenção sustentada, o que parece se manifestar neste funcionamento cognitivo é uma atenção que se mantém fixa, respondendo de modo saltitante ao apelo dos estímulos. Compreende-se então por que é mais fácil se distrair com o próprio pensamento do que nas idas e vindas do computador.

É interessante perceber que para E4 as idas e vindas do computador não representam necessariamente paradas em seu estudo, sugerindo um modo de estudar também saltitante. Tal observação nos faz pensar no problema da atenção dividida. Menos do que uma exceção, a atenção dividida parece participar cada vez mais do funcionamento atencional contemporâneo. Citamos Almeida e Eugênio a esse respeito:

Importa chamar a atenção, aqui, para o fato de que tanto a mídia atual quanto os especialistas vêm apontando a particular aptidão dos jovens de classe média dos grandes centros urbanos em fazer uso simultâneo de dispositivos eletrônicos, tais como telefone celular, computador, som e TV. O uso simultâneo desses 
recursos também se estende à realização de tarefas e obrigações que exigem concentração, como estudar. (Almeida \& Eugênio, 2006, p. 54)

Alguns chegam a se referir a uma geração multitarefa (Wallis, 2006). Este funcionamento dividido repercute sobre a concentração e a sustentação atencional. Os teóricos da atenção defendem que a atenção dividida conduz a um declínio tanto da concentração quanto da possibilidade de sustentação da atenção (Camus, 1996). No entanto, a análise das entrevistas faz ver que, para além da diminuição da concentração e da sustentação atencional, está surgindo uma nova relação entre atenção e estudo. Trata-se da aceitação de uma atenção suficiente. Isto é, uma atenção que não é plena, mas que também não está ausente. Citamos:

Eu acho que eu estudo melhor quando eu tô...é... prestando não atenção demais, nem de menos no estudo. Quer dizer, quando tem...se tiver só um silêncio absoluto e eu com o livro, eu não vou conseguir ficar focado muito tempo. ... Ao mesmo tempo, se tiver muito barulho e tal, distração, eu também não vou conseguir ficar focado. Então eu acho que teria que ter moderadamente com algum, sabe? Outras coisas e tal, outros estímulos. Sabe? Pra poder dar uma, sabe? É. Normalmente não coisa de mais nem coisa de menos me estimulando assim. (E4)

Ainda sobre isso outro estudante afirma:

É raríssimo eu me concentrar cem por cento. $E$ raríssimo também eu não me concentrar em nada. É sempre uma concentração ali: entre o nada e o cem por cento. E sempre acontece. Quando tá no nada ai eu vou: 'Pera, parou, vamos lá', volto pro texto. Quando tá no cem por cento, aí é fantástico, algo tá acontecendo, aí você pode ter certeza que algo tá acontecendo de fantástico na minha vida. E fora isso, é o normal. Não me incomodo porque é o normal. É o normal pra mim. (E3)

Será que o acoplamento da cognição com o computador conduz necessariamente o estudo por uma via que o afasta do pensamento, da problematização e do aprofundamento? Ou será que existem brechas para que novas relações entre estudante e estudo sejam estabelecidas? Relações que invertam as prioridades. Que tragam à cena a experiência, colocando em primeiro plano o pensamento e deixando a tarefa e a performance para segundo plano?

\section{Política cognitiva curiosa e desejosa de saber}

Com o intuito de encontrar brechas a partir das quais possam nascer outras relações entre estudantes e estudo, nos deparamos mais uma vez com a fala de um estudante. Essa nos mostra uma relação com o conhecimento que não se contenta com as respostas dadas, sendo a pesquisa algo necessário. Citamos:

Foi por causa do [professor], fiz a pergunta pra ele. A pergunta era: qual era a diferença, exatamente a diferença entre um mapeamento cerebral dinâmico, que é o do Luria, e o mapeamento cerebral funcional específico, que é o do Brocat. Ele falou: "Essa resposta é complexa. Eu já tô descendo, aula que vem a gente fala disso". Eu falei: "tá bom”. Só que aí eu cheguei em casa, tava com isso na cabeça e resolvi ler. (E4)

O aluno perguntou ao professor e este não pode ou não quis responder na hora. Aqui seria interessante pensar tambémoquanto as práticas de ensino repercutem sobre as práticas de estudo e, consequentemente, sobre a produção da atenção. Embora esse não seja o nosso foco neste momento, convém não perder de vista este importante aspecto. No caso do estudante em questão, ao invés de se conformar com a limitação imposta pelo professor, ele foi procurar saber a resposta para o seu problema. Ora, será que aí não está a fresta que procurávamos? Esta atitude aponta para uma experiência de problematização que insiste e gera um movimento de busca da solução que merece, a nosso ver, ser sublinhada e valorizada. Pode representar o desvio que aponta a presença do estudo na via da experiência e do pensamento. Sobre isso é interessante perceber o quanto o acoplamento da cognição com o computador-internet concorre para a produção dessa política cognitiva curiosa e desejosa de saber, com diferentes desdobramentos possíveis.

O estudante tinha o livro, o que facilitou a busca. Mas muitas vezes a pesquisa é realizada no computador, através das ferramentas de busca da internet. Sobre isso é interessante o que diz um estudante:

\begin{abstract}
Ah, eu boto no Google. E ai vem o Wikipédia, vem $o$ site de pessoas que falam sobre isso também ou que escreveram. Ai eu até fico sabendo de gente que tá estudando esses temas que eu me interesso, mas que ainda não, que aqui na faculdade não tem, não escuto falar. Por ai eu vou, mas sem essa... sem esse enquadramento assim da... sem nenhum método, sem nada, só porque eu quero. E eu faço isso quando eu tenho tempo, quando eu quero e sem essa pressão também de ter que... Pressão não, mas, assim, essa exigência de eu ter que tá apresentando pra alguém. (E11)
\end{abstract}

Este estudante sente que muitas vezes aquilo que a sua faculdade oferece é insuficiente, porém, através da internet e do tipo de acesso à informação que esse dispositivo permite, consegue se aventurar 
por outros assuntos. Entretanto, nesse caso, não se trata de nada muito sistemático ou aprofundado, conforme o próprio estudante relata. Existe uma curiosidade e talvez até uma necessidade de saber mais. Como tudo o que se deseja está à distância de um clique, então se clica. Isso não significa que ele vá se deter para pensar, ir além, ou que esse clique terá maiores desdobramentos. Vejamos a fala de outro estudante:

\begin{abstract}
Ah! É. Às vezes eu escuto uns nomes assim que eu não sei. Todo mundo fala muito do Kant, 'aí gente, quem é Kant? Pelo amor de deus', [risos] ai chego na Internet... ai chego em casa vou na Internet pesquisar. Ou às vezes a professora fala uma palavra que eu não sei assim, ai eu anoto pra poder pesquisar. Isso eu faço. Ai antes eu ficava meio desesperada que todo mundo sabia todas as linhas da psicologia e eu não sabia nada. Qual a diferença de uma e outra pra não sei o quê? Eu falei: 'o que é isso?' Aí eu comecei a pesquisar assim. Mas mais por interesse de eu não... sabe? De você poder conversar e saber conversar, não ficar igual a uma idiota, sabe? Sem ter o que falar. Isso eu faço. (E5)
\end{abstract}

Assim, essa política cognitiva orientada pela curiosidade e pelo desejo de saber pode produzir tanto o pensamento, a problematização e o aprofundamento quanto permanecer referida a uma relação superficial com o conhecimento. Consideramos então que a facilidade no acesso às informações possibilitado pelas novas tecnologias tem dupla implicação para a cognição. Por um lado, suscita a curiosidade e o desejo de saber. Por outro, como tudo está ali, pode também produzir um sentimento de que não é preciso ir muito além ou tentar entender algo mais cuidadosamente, pensar a respeito, deter-se por mais tempo naquilo. Afinal quando quiser encontrar novamente, basta clicar:

Eu acabo... 'ah, tá achei isso interessante', ai guardo. Ai guardo nos favoritos, ai guarda... De alguma maneira arquiva aquilo para em algum momento, ah, tipo, tá, vou ler... enfim... Não tenho tido nem... às vezes recebo e-mail mesmo interessante... não tenho tido tempo de... dar conta disso tudo. Mas eu dou alguma, dou um jeito de arquivar aquilo ali pra num momento posterior tentar pelo menos... ver aquilo de novo. (E2)

Tendemos a concluir que o não aprofundamento nos assuntos do qual tantos professores se queixam tem menos a ver com a tradicional oposição entre um estudo que envolve a compreensão e outro que envolve memorização e mais com a consciência de que o conhecimento está à distância de um clique.

\section{Considerações finais}

Após este percurso, podemos dizer que as práticas de estudo dos estudantes de psicologia do município do Rio de Janeiro na contemporaneidade estão produzindo de maneira hegemônica uma atenção saltitante e sem ritmo. Revelam assim uma relação entre estudante e estudo que se orienta mais pela tarefa e performance do que pelo pensamento, problematização e experiência. Conforme argumentamos, este funcionamento atencional parece possuir estreita ligação com os dispositivos usados pelos estudantes em suas práticas de estudo. Em outras palavras, a atenção saltitante e sem ritmo parece relacionar-se ao modo como as novas tecnologias, e em especial o computador-internet, capturam a atenção. Fixando e fazendo saltar de um foco a outro. No entanto, essas novas tecnologias podem concorrer também para a produção da política cognitiva curiosa e desejosa de saber. Essa, a nosso ver, pode se constituir numa brecha, podendo concorrer para a produção de novas relações entre estudantes e estudo. Relações que apontem antes para o pensamento que para a tarefa. Se colocadas em ação, essas poderão fazer surgir novos funcionamentos atencionais.

Portanto, ao nos debruçarmos sobre a cognição contemporânea, parece que cada vez mais encontraremos a presença das novas tecnologias. Guattari, em um texto publicado em 1988, já apontava para a necessidade de pensarmos dali por diante numa subjetividade produzida na interdependência com a infinidade de sistemas maquínicos que, naquele momento, começavam a se desenvolver e popularizar: "Nenhum campo de opinião, de pensamento, de imagem, de afectos, de narratividade pode, daqui para frente, ter a pretensão de escapar à influência invasiva da 'assistência por computador', dos bancos de dados, da telemática, etc." (Guattari, 1993, p.177). As novas tecnologias não são em si positivas ou negativas. Desafiam-nos a sempre a investigar quais os efeitos que estão produzindo sobre a cognição e a subjetividade.

\section{Agradecimentos}

Este trabalho foi financiado pelo CNPq. É parte dos resultados da tese "Sobre as práticas de estudo dos estudantes de psicologia: uma cartografia da cognição contemporânea" defendida no programa de PósGraduação em Psicologia da UFRJ, sob orientação da professora Virgínia Kastrup. 


\section{Referências}

Almeida, M. I. \& Eugenio, F. (2006). O espaço real e o acúmulo que significa: uma nova gramática para se pensar o uso jovem da Internet no Brasil. In A. M. Nicolaci-da-Costa (Org.), Cabeças Digitais: o cotidiano na era da informação (pp.4980). Rio de Janeiro: Ed. PUC-Rio; São Paulo: Loyola.

Cabral, M. C. (2006). Encontros que nos movem: a leitura como experiencia inventiva. Tese de Doutorado, Programa de PósGraduação em Psicologia, Universidade Federal do Rio de Janeiro, Rio de Janeiro, RJ.

Camus, J. F. (1996). La psychologie cognitive de l'attention. Paris: Armand Colin.

Depraz, N., Varela, F., \& Vermersch, P. (2002). On becoming aware: a pragmatic of experiencing. Amsterdam/ Philadelphia: John Benjamins.

Gomez-Iniguez, C., Carbonel-Vayá, E. J. \& Martin del Rio, B. (1999). Análisis conceptual del término vigilância desde princípios del s. XX hasta la actualidad: uma perspectiva histórica. Revista de História de La Psicologia, 20(3-4),414428.

Guattari, F. (1993). Da produção da subjetividade. In A. Parente (Org.), Imagem máquina. (pp.177-191). Rio de Janeiro: Ed.34.

James, W. (1924). Psicología pedagógica. Madrid: Biblioteca internacional. (Original publicado em 1899)

James, W. (1952). The principles of psychology. Chicago: Enciclopédia Britannica. (Original publicado em 1890)

Kastrup, V. (2004). A aprendizagem da atenção na cognição inventiva. Psicologia \& Sociedade, 16(3), 7-16.

Kastrup, V., Tedesco, S., \& Passos, E. (2008). Politicas da cognição. Porto Alegre: Sulina.

Lecerf, E. (2006). Vigilance et attention, les deux limites extrêmes du travail chez Simone Weil. Publications de la Faculté de philosophie de l'Université Jean Moulin Lyon 3, Série annales, 51-71.

Myra y Lopes, E. (1968). Como estudar e como aprender. São Paulo: Mestre Jou. (Original publicado em 1948)
Rosário, P. S. (2004). (Des) venturas do Testas: estudar o estudar. Portugal: Porto.

Vermersch, V. (2000). L'entretien d'explicitation. Issy-lesMoulineaux : ESF.

Wallis, C. (2006). The multitasking generation. Time. Acesso em 19 de março, 2009, em http://www.time.com/time/ magazine/article/0,9171,1174696,00.html

Weil, S. (1979). Experiência da vida de fábrica. In E. Bosi (Org.), A condição operária e outros estudos sobre a opressão (pp. 129-146). Rio de Janeiro: Paz e Terra.

Recebido em: 22/02/2010

Aceite em: 14/07/2010

Beatriz Sancovschi é Mestre e Doutora em Psicologia pela pós-graduação em Psicologia da UFRJ e professora adjunta do IP-UFRJ. Endereço: Rua Garibaldi, 133/803, Bl. A

Tijuca. Rio de Janeiro/RJ, Brasil. CEP 20511-330. Email: beatrizsancovschi@gmail.com

Virgínia Kastrup é Doutora em Psicologia (PUC-SP) e professora do Programa de Pós-Graduação em Psicologia da UFRJ. Endereço: Rua General Cristóvão Barcelos 280, apto. 603. Laranjeiras. Rio de Janeiro/RJ, Brasil. CEP 22245-110. Email: virgínia.kastrup@gmail.com

\section{Como citar:}

Sancovschi, B. \& Kastrup, V. (2013). Práticas de estudo contemporâneas e a aprendizagem da atenção. Psicologia \& Sociedade, 25(1), 193-202. 